\title{
A Comparative Study Of Ethical Values Of Business Students: American Vs. Middle Eastern Cultures
}

Michael Shurden, Lander University, USA

Susan Shurden, Lander University, USA

Douglass Cagwin, Zayed University, Dubai, UAE

\begin{abstract}
Business schools must prepare students to face the world and yet maintain strong ethical convictions. The question of ethics in the business environment is not exclusive to the United States. Ethical business behavior is a multinational issue, and all business schools world-wide must deal with this issue. However, cultural differences often define acceptable ethical behavior. For example, the acceptable amount of a "token" gift from one party to another is an ethical issue. Some American businesses do not even allow employees to accept gifts from clients, while within other businesses, both National and International, it is an acceptable tradition. Bribery of foreign officials during the 1970's addressed this issue of what is acceptable in the form of gifts and/or payments between public officials when they initiated the Foreign Corrupt Practices Act of 1977, which prohibits the "paying, offering, promising to pay (or authorizing to pay or offer) money or anything of value.....to corrupt payments to a foreign official, a foreign political party or party official, or any candidate for foreign political office" (usdoj.gov). Ethical situations involving foreign officials and diplomats in other countries can also affect business transactions, which may ultimately be controlled by graduates from business schools in our colleges and universities. Consequently, the question is "What are the differences in ethical perceptions and values between cultures?" Once this question is addressed, business professors can adapt their teaching methods to help shape and mold the ethical values of business students. In a search for the answer to these ethical questions between cultures, the authors representing two universities, decided to conduct a small research sample on their business students. One of the colleges is a small public university located in the Southeastern United States, and the other is a university located in the Middle Eastern country of the United Arab Emirates (UAE). A small sample of students from selected business classes of each school were given a 16 question ethics quiz which had been taken from The Wall Street Journal. The questions ranged from personal use of company e-mail on the job to whether or not the individuals had lied about sick days or had taken credit for another's work. The authors hoped to determine whether there were any significant differences between the answers given from the two schools pertaining to these types of ethical issues and to learn to what extent the different cultures had in shaping the ideas of these future business professionals.
\end{abstract}

Keywords: ethics, students, business

\section{INTRODUCTION}

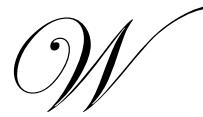

ebster's dictionary defines ethics as a "discipline dealing with good and evil and with moral duty; moral principles or practice." However, the definition of ethics may vary from company to company. For example, Eli Lilly Company stated that ethics means "No Lilly employees should do anything, or be expected to take any action that they would be ashamed to explain to their family or friends." Eastman Kodak has a business ethics policy, which emphasizes that Kodak's business practices throughout the world are to be conducted in a manner, which is above reproach. General Dynamics' definition of ethics according to their ethics Vice President is "telling the truth and being fair and doing no voluntary harm." This means that one should not allow themselves to get into a position that compromises his/her judgment, such as the position in which a supplier may find oneself when taking the potential buyer of their product to lunch. And then there is the most 
basic question that Electronic Data Systems uses to judge their ethic's policies, "Would we want to do business with ourselves?" (Abend, 1988).

The ethics question in the business environment seems to cycle back through time. Bribery of foreign officials and the Watergate scandal of the 1970's (Abend, 1988) were followed in the late 1980's by the secret world of Michael Milken and Ivan Boesky and their lucrative insider trading schemes on Wall Street (Stewart, 1991). These situations brought about investigations from the government by the Treadway Commission, which concluded that business students needed to be taught more about ethical situations in order to avoid them (Kullberg, 1988). This trend seemed to pass through business schools for a while, but now it seems to have lost momentum. In 2001, big scandals again rocked the business world. We observed Enron executives and their accountants, Arthur Anderson, be accused and charged with serious infractions in reporting financial information by hiding billions of dollars in debts behind fictitious partnerships (Morse, 2003). About the same time, WorldCom's Chief Financial Officer, Scott Sullivan, acknowledged over-reporting of profits in WorldCom's financial statements. The same group of external auditors failed to detect the impropriety (Ripley, 2003). And, then while the business world was still trying to process the unreliability of financial reporting, Martha Stewart was indicted and found guilty, along with her stockbroker, Peter Bacanovic, for conspiracy, obstruction of justice and making false statements in the sale of Stewart's shares of Imclone stock (cnn.com, 2004).

The incidences mentioned above are referred to as "white collar" crimes. Our legal system typically sets the basis for what is considered offensive in our society, defined by Kullberg (1988) as "illegal behavior or blatant misconduct". However, because of the diverse nature of the subject matter of white-collar crime, it is often difficult to set a definition to the term (Chibe, 2006). Typically white-collar crimes include insider trading, embezzlement, bribery, forgery, fraud, and computer crimes. Current definitions of white collar crime include health care fraud, securities fraud, and environmental crimes (Chibe, 2006). The term came to be in 1939 when it was noted that the perpetrators of these crimes wore white-collar shirts, and that they were professionals in the business world, such as lawyers, bankers, and now accountants (thefreedictionary). Additionally, white collar crime is becoming a global issue, and a 2006 Symposium entitled "The Changing Face of White-Collar Crime" actually covered this issue and how the Foreign Corrupt Practices Act addresses the concern (Chibe, 2006).

While the above improprieties involve American businesspeople and businesses, it has been observed by the authors that there is an increasing influx of foreigners purchasing and operating businesses in the United States. These businesses range from small convenience stores, hotel chains, and tourist shops to major industries such as Fuji, a Japanese owned manufacturer of camera equipment and film. Many of the small convenience stores, hotels, and tourist shops that were aforementioned are owned by Middle Eastern businessmen and operated by their families. The question arises as to whether or not there are ethical differences between cultures, particularly between Middle Eastern cultures and American cultures.

Before answering this question, it would be helpful to analyze the thought processes that an individual uses when approaching and solving ethical dilemmas. As an individual encounters an ethical situation, whether black/white (or a gray, unclear issue), they mentally analyze the options available and try to solve the problem in one of three ways according to Kullberg (1988). From personal observation and communication with Middle Eastern students, one of the authors noted that Middle Eastern individuals typically think in black/white. Either a situation is acceptable or it is "haram", meaning forbidden by their Muslim religion. This author who currently lives and teaches in the Middle East believes that the exposure to western values that the girls get in college has started to create a gray area, so that they are interpreting situations in different ways. With that explanation in mind, one model in which people approach and solve ethical situations is referred to as the "utility" model. Utility in the economic sense means "satisfaction". Using this model would mean that a person would approach the problem by trying to satisfy the largest number of people or as Kullberg says "maximize happiness for the greatest number of people." Another model is referred to as the "enlightened self-interest" model in which the person making the ethical decision would "pursue self-interest in a way that minimizes harmful consequences for others." The final model is one that many Americans have learned throughout the years, from family, teachers, and religion. It is the "Golden Rule" model, which takes the Biblical approach of "treat others as you would want to be treated" (Kullberg, 1988). 
After identifying these three models, it is possible to try and explore the minds of the business students that have been surveyed. While Middle Eastern students might use one of the first two approaches in solving ethical dilemmas, the third approach needs to be analyzed further as it is based on a religion that differs from their own. Virtually all native students in the UAE are Muslim and follow the Islam beliefs based on the Quran and teachings of Muhammad, which in many regards has stricter religious views than Christianity. However, one possibility in this regard is the aspect of tolerance, which is discussed by Verkuyten and Slooter, (2007). In their article they address the fact that religious, cultural, and ethnic differences are currently a "hot topic". Verkuyten and Slooter, (2007) conclude that tolerance seems to increase with increased education, so the authors of the current study assume that if living and working in the United States, Muslims could tolerate the "Golden Rule" model as part of their ethical reasoning. However, a further study of the religious beliefs of Muslims finds that they too have a principle similar to the "Golden Rule". This Muslim principle is a form of the "Ethic of Reciprocity," common to almost all, and states that "Not one of you is a believer until he loves for his brother what he loves for himself" (Fourth Hadith of anNawawi 13). Consequently, the third model of treating others as you wish to be treated would most likely be a principle that is prevalent and often used in Middle Eastern Culture.

\section{THE STUDY}

For purposes of the study, two small universities were selected. One set of participants is representative of a small, public university located in the southeastern United States. The other set represents a Middle Eastern university located in Dubai, an emirate of the UAE. The university located in UAE is an all female university while the U.S. university is coed. Some of the questions have been modified because of currency differences and religious beliefs. These questions are indicated by an asterisk (*). The currency of the UAE is the Dirham, and the question was changed in order for the UAE students to comprehend the currency difference, and the denomination was adjusted so that it would be equivalent to the question asked the U.S. students. The value of the Dirham is $3.673 \mathrm{dhs}$ to $\$ 1$.

Additionally, the question regarding visiting a pornographic web site was slightly modified as pornographic websites are blocked by the UAE government and theoretically unavailable for access. However, the question was modified to read "Is it unethical to visit dating websites using office equipment?" This question would be comparable to our pornographic website question considering the fact that visiting a dating web-site is venturing into forbidden area and is very close to the U.S. idea of pornographic web-sites. This study was conducted on an all female population within the UAE university, and in the Middle East, female students are forbidden to date, or even be alone with an eligible male. Other than family, no touching is allowed by any outsider. Punishment for any female venturing into these sites would be much like with our teen-agers, resulting in a loss of privileges such as taking away their car.

With these clarifications in mind, the 16 question ethics quiz was administered to a small group of students from the American university and the Middle Eastern university. The classes surveyed at the American university consisted of both upper and lower level business classes consisting of coed students of all socioeconomic groups. Those surveyed in the UAE consisted of upper level business classes, females, generally of upper-middle socioeconomic status. Eighty seven students were surveyed at the American university, and fifty-seven surveys were collected at the UAE University. Table I shows the results of the surveys with regard to the two colleges.

Although many similarities may be noted, there were apparent differences in the responses. The first six questions deal primarily with the use of office technology. Approximately eighty-two percent of the respondents from the American university believe it is wrong to play games on the office computer during work, while sixtythree percent of the UAE students believe this situation is wrong. The significant difference in the answer to this question could be because of the fact that the UAE students are all female, and Muslim women are rarely allowed to work outside of the home. The estimate of the percentage of those holding jobs prior to entering college is $5 \%$. Consequently, issues of what is or is not tolerated in the work community, as well as possible "downtime" at work, are areas to which they are unfamiliar. Another interpretation for the difference is that the UAE students read the question as meaning "playing games at times when you are supposed to be working", definitely defining the situation as unethical in their opinion; otherwise, they see no reason for asking the question. 
Table I

\begin{tabular}{|c|c|c|c|}
\hline & \multicolumn{3}{|c|}{ College } \\
\hline \multirow{2}{*}{\multicolumn{2}{|c|}{ Questions }} & USA & UAE \\
\hline & & Yes & Yes \\
\hline \multicolumn{2}{|l|}{ 1. Is it wrong to use company e-mail for personal reasons? } & $58 \%$ & $61 \%$ \\
\hline \multicolumn{2}{|l|}{ 2. Is it wrong to use office equipment to help your children or spouse to do schoolwork? } & $64 \%$ & $68 \%$ \\
\hline \multicolumn{2}{|l|}{ 3. Is it wrong to play computer games on office equipment during the workday? } & $82 \%$ & $63 \%$ \\
\hline \multicolumn{2}{|l|}{ 4. Is it wrong to use office equipment to do internet shopping? } & $81 \%$ & $74 \%$ \\
\hline \multicolumn{2}{|l|}{ 5. Is it unethical to blame an error you made on a technological glitch? } & $78 \%$ & $84 \%$ \\
\hline \multicolumn{2}{|l|}{ 6. Is it unethical to visit pornographic web sites using office equipment?* } & $99 \%$ & $86 \%$ \\
\hline \multirow[t]{3}{*}{ 7. What's the value at which a gift from a supplier or client becomes troubling?* } & $\$ 25.00$ & $33 \%$ & $21 \%$ \\
\hline & $\$ 50.00$ & $37 \%$ & $14 \%$ \\
\hline & $\$ 100.00$ & $30 \%$ & $65 \%$ \\
\hline \multicolumn{2}{|l|}{ 8. Is a $\$ 50.00$ gift to a boss unacceptable?* } & $34 \%$ & $53 \%$ \\
\hline \multicolumn{2}{|l|}{ 9. Is a $\$ 50.00$ gift from the boss unacceptable?* } & $27 \%$ & $37 \%$ \\
\hline \multicolumn{2}{|l|}{ 10. Of gifts from suppliers: Is it OK to take a $\$ 200$ pair of football tickets?* } & $40 \%$ & $32 \%$ \\
\hline \multicolumn{2}{|l|}{ 11. Is it OK to take a $\$ 120$ pair of theater tickets?* } & $43 \%$ & $44 \%$ \\
\hline \multicolumn{2}{|l|}{ 12. Is it OK to take a $\$ 100$ holiday food basket?* } & $45 \%$ & $35 \%$ \\
\hline \multicolumn{2}{|l|}{ 13. Is it OK to take a $\$ 25$ gift certificate?* } & $72 \%$ & $58 \%$ \\
\hline \multicolumn{2}{|l|}{ 14. Can you accept a $\$ 75$ prize won at a raffle at a supplier's conference?* } & $92 \%$ & $68 \%$ \\
\hline \multirow{2}{*}{\multicolumn{2}{|c|}{$\begin{array}{l}\text { 15. Due to on-the-job pressure, have you ever abused or lied about sick days? } \\
\text { 16. Due to on-the-job pressure, have you ever taken credit for someone else's work or idea? }\end{array}$}} & $30 \%$ & $68 \%$ \\
\hline & & $4 \%$ & $19 \%$ \\
\hline
\end{tabular}

The Wall Street Journal Ethics Quiz, October 21, 1999.

Another area of difference was the value of a gift which would become troublesome. Nearly two-thirds of the UAE students believe a gift is troublesome if it reaches approximately $\$ 100$. The American students were somewhat evenly spread across the three choices, with approximately $30 \%$ being troubled at a $\$ 100$ gift. At all three levels of accepting gifts from a supplier, the UAE students had more ethical responses. In contrast to previous responses, 34\% of the Americans believe a \$50 gift TO your boss is unacceptable while 53\% of the UAE students believe this amount is unacceptable. Also, $72 \%$ of the Americans believe it is ok to accept a $\$ 25$ gift certificate, as compared to $58 \%$ of the Middle Easterners. Ninety-six percent of the American students believe it is acceptable to receive a $\$ 75$ prize at a supplier's conference compared to a $68 \%$ acceptable response for the UAE students. The high percentage of differences in this response, with the UAE students having a higher ethical perception, may be due to the aforementioned issue of bribery being a significant international topic. It is noted by one of the authors that UAE students have trouble with this aspect of gifts being given and received. They first ask themselves "Why is the gift made? Is it a bribe?" The amount to them is not as important as the motivation behind the gifts, while in the United States we make rules with limits on gifts, rather than determine the motivation. The author notes that his students will bring him a "latte" to class, and in their way they are just being nice. To refuse to accept this gesture would be hurtful to them as their intent is not to bribe. However, if in the UAE there were separate graders of papers other than the teacher, to offer the grader a "latte" would be interpreted as a bribe because a direct transaction is going on. So accepting a bribe is not being honest, while accepting a gift is normal.

One of the most surprising results was the difference in responses relating to abusing or lying about sick days. Over two-thirds of the UAE students have abused or lied about sick days compared to $30 \%$ of the American students. Approximately 19\% of the UAE students have taken credit for someone else's work or ideas compared to only 4\% for the American students. While American students may or may not have answered these questions with complete honesty, the UAE students probably answered with full comprehension and honestly. In addition to the various aspects of gift giving, they are taught to be honest in all dealings - they may hedge or exaggerate with their teacher, but they would never tell the teacher an outright lie. Additionally helping each other is expected, while doing their own work at this particular university is a new concept to them. However, a much larger sample size is needed to be able to more fully explain the differences in the responses between the two colleges. 
Table II presents a comparison of the students surveyed from the two universities and how American executives responded to the quiz. Numerous differences can be noted throughout the quiz. Many of these differences can be explained by the fact that students lack or have limited real-world experiences that actually place them in these situations. For example, students do not sit in offices with computers in front of them all day long. They may not realize how easy it is to play a computer game or do some Internet shopping during slow times.

\section{Table II}

\begin{tabular}{|c|c|c|c|c|}
\hline \multicolumn{2}{|l|}{ Questions } & USA & Exe. & UAE \\
\hline & & Yes & Yes* & Yes \\
\hline \multicolumn{2}{|l|}{ 1. Is it wrong to use company e-mail for personal reasons? } & $58 \%$ & $34 \%$ & $61 \%$ \\
\hline \multicolumn{2}{|l|}{ 2. Is it wrong to use office equipment to help your children or spouse to do schoolwork? } & $64 \%$ & $37 \%$ & $68 \%$ \\
\hline \multicolumn{2}{|l|}{ 3. Is it wrong to play computer games on office equipment during the workday? } & $82 \%$ & $49 \%$ & $63 \%$ \\
\hline \multicolumn{2}{|l|}{ 4. Is it wrong to use office equipment to do internet shopping? } & $81 \%$ & $54 \%$ & $74 \%$ \\
\hline \multicolumn{2}{|l|}{ 5. Is it unethical to blame an error you made on a technological glitch? } & $78 \%$ & $61 \%$ & $84 \%$ \\
\hline \multicolumn{2}{|l|}{ 6. Is it unethical to visit pornographic web sites using office equipment? } & $99 \%$ & $87 \%$ & $86 \%$ \\
\hline \multirow[t]{3}{*}{ 7. What's the value at which a gift from a supplier or client becomes troubling? } & $\$ 25.00$ & $33 \%$ & $33 \%$ & $21 \%$ \\
\hline & $\$ 50.00$ & $37 \%$ & $33 \%$ & $14 \%$ \\
\hline & $\$ 100.00$ & $30 \%$ & $33 \%$ & $65 \%$ \\
\hline \multicolumn{2}{|l|}{ 8. Is a $\$ 50.00$ gift to a boss unacceptable? } & $34 \%$ & $35 \%$ & $53 \%$ \\
\hline \multicolumn{2}{|l|}{ 9. Is a $\$ 50.00$ gift from the boss unacceptable? } & $27 \%$ & $12 \%$ & $37 \%$ \\
\hline \multicolumn{2}{|l|}{ 10. Of gifts from suppliers: Is it OK to take a $\$ 200$ pair of football tickets? } & $40 \%$ & $70 \%$ & $32 \%$ \\
\hline \multicolumn{2}{|l|}{ 11. Is it OK to take a $\$ 120$ pair of theater tickets? } & $43 \%$ & $70 \%$ & $44 \%$ \\
\hline \multicolumn{2}{|l|}{ 12. Is it OK to take a $\$ 100$ holiday food basket? } & $45 \%$ & $35 \%$ & $35 \%$ \\
\hline \multicolumn{2}{|l|}{ 13. Is it $\mathrm{OK}$ to take a $\$ 25$ gift certificate? } & $72 \%$ & $45 \%$ & $58 \%$ \\
\hline \multicolumn{2}{|l|}{ 14. Can you accept a $\$ 75$ prize won at a raffle at a supplier's conference? } & $92 \%$ & $40 \%$ & $68 \%$ \\
\hline \multicolumn{2}{|l|}{ 15. Due to on-the-job pressure, have you ever abused or lied about sick days? } & $30 \%$ & $11 \%$ & $68 \%$ \\
\hline \multicolumn{2}{|l|}{ 16. Due to on-the-job pressure, have you ever taken credit for someone else's work or idea? } & $4 \%$ & $4 \%$ & $19 \%$ \\
\hline
\end{tabular}

* Results from a study published in The Wall Street Journal, October 21, 1999.

The same is true in regard to gifts and entertainment. Student's responses are based more on the abstract rather than reality since most are not in executive positions. American executives are often exposed to these types of situations and realize how difficult these decisions can actually be. The responses of the students indicate a stronger ethical consideration than the executives when it comes to using technology at the office. However, the results were mixed regarding supplier relations. An additional survey needs to be conducted in this area of the Middle Eastern executive, with an analysis being made which would put the study on more equitable terms.

\section{CONCLUSIONS}

The differences that have been observed between the American and Middle Eastern students have raised enlightenment on the cultural differences between the two counties. While it is doubtful that many of the UAE students will live and work in the United States because the idea of living away from family, except on a temporary basis, is not an accepted practice, much can be learned from the study as to the ethical perceptions to which they adhere. Additionally, it is not known if the females surveyed will actually work in the business world. If unmarried, the oldest brother will usually determine what jobs, if any can be accepted. If they marry, it is up to the husband if they may work outside of the home. If they enter the business world, the females in the sample will almost all work in accounting or human resources and would be called professionals. There is a program in the UAE called Emiratisation where a set percentage of human resource employees must be Emiratis, so approximately $60 \%$ would work, and of that $60 \%$, approximately $2 / 3$ would work for the government in either of the aforementioned areas.

Consequently, as educators in either culture, we are preparing business students to enter the business world, and, as such, we have a significant impact on their training and ethical perceptions. Obviously, ethics does begin at home with early teaching from parents, religious institutions, and grade school teachers. However, it has been 
argued that ethics cannot be taught past a certain age. Kullberg (1988) has declared this untrue, and ethics education has and should continue into the college years. Kullberg and the current authors definitely recommend more college classes on ethics, as well as discussions and ethical scenarios being incorporated into all business classes. However, once students enter the business world, each company is responsible for revealing to their employees what is acceptable and unacceptable behavior in their business environment. In prior years, General Dynamics installed ethics hotlines where employees could pick up the phone and contact someone within the company on how to handle certain ethical dilemmas. Also, ethics guidelines in the form of written statements were given to employees of Eastman Kodak and Eli Lilly. Employees were to carefully study what the company expected of them in certain situations. Lastly, acknowledgement by signature has proven effective for Hallmark Cards and Solutia (formerly Monsanto) where top management acknowledged compliance to ethical standards. Such standards for Hallmark Cards included what is acceptable as a gift or gratuity to an employee, and that they had not violated those policies (Abend, 1988).

Additionally an increase in the enforcement of penalties in the form of fines and prison terms for violations of statutes such as the Foreign Corrupt Practices Act has brought awareness to the seriousness of ethics and morals in our cultures. Criminal or civil penalties may be imposed for violation of the act, which pertains to direct or indirect bribery of public officials by any type of business entity be it public or non-public. The business could be accessed as high as a $\$ 2,000,000$ fine, while any officer, director or stockholder could be accessed $\$ 100,000$ and imprisoned for up to five years. A further note is that individual fines cannot be paid by the firm, thus imposing a significant hardship on the individual involved (Goudy, 2003)

In conclusion, business students should be made aware that trying to avoid violating a policy is not always enough for a company. Many times the mere appearance of a conflict to the ethical standards of a company can lead to trouble. Thus, avoiding the uncompromising situation altogether, and erring on the side of cautiousness is always advised.

\section{AUTHOR INFORMATION}

Mike Shurden is a Professor of Management at Lander University in Greenwood, SC. He has previous teaching experience at the University of North Alabama in Florence, and at Louisiana Tech University in Ruston. Dr. Shurden received both his undergraduate business degree and MBA from Delta State University in Cleveland, MS. He received his DBA from Louisiana Tech University. He has over twenty six years of teaching experience at the college level. He has numerous academic publications over his career. His work can be found in journals such as Business Horizons and the Academy of Educational Leadership Journal. Dr. Shurden primarily teaches quantitative management, and his research focus is on educational leadership.

Susan Shurden is an Instructor of Accounting at Lander University in Greenwood, SC. She has previous teaching experience at Erskine College in Due West, SC. Mrs. Shurden received her undergraduate Accounting degree and Masters in Professional Accountancy (MPA) from Louisiana Tech University in Ruston. She is a CPA through the state of Louisiana (status inactive) and is currently working on her Ph.D in Educational Leadership at Clemson University. She has eighteen years of teaching experience at the college level. Mrs. Shurden primarily teaches in financial accounting. Her research focus is on ethics in higher education.

Douglass Cagwin is Associate Professor of Accounting at Zayed University in Dubai. He has previous teaching experience at Lander University, Greenwood, South Carolina and at the University of Texas at Brownville. Dr. Cagwin received Masters and Ph.D. degrees in Accounting from the University of Arkansas, and his undergraduate accounting degree from Iowa State University. He has over twenty years of controllership experience in manufacturing and distribution and three years experience in public accounting. Dr. Cagwin primarily teaches managerial accounting, auditing, and accounting information systems. His research focuses on determining the net value obtained from implementation of sophisticated cost accounting systems. 


\section{REFERENCES}

1. Abend, J. (1988). Corporate ethics: An overview. New Accountant, 4(1), 4-11.

2. Chibe, R. J. (2006). A golden age of white-collar criminal prosecution. The Journal of Criminal Law \& Criminology, 96(2), 389-395.

3. Goudy, G. (2003). Name an oxymoron: Business ethics. Business Credit, 105(3), 67-71.

4. Fourth Hadith of an-Nawawi 13. Retrieved December 14, 2007, from http://www.religoustolerance.org/comp_isl_chr.htm//.

5. http://encyclopedia.thefreedictionary.com/White-collar+crime/, accessed 6/5/05.

6. $\quad$ http://www.usdoj.gov/criminal/fraud/docs/dojdocb.html, accessed 11/28/07.

7. Kullberg, D. R. (1988). Right and wrong: How easy to decide? New Accountant, 4(1), 16-20, 37.

8. $\quad$ Mish, F. C. (Ed.), The Merriam Webster Dictionary. (Springfield, Massachusetts).

9. Morse, J., \& Bower, A. (2003). The party crasher. Time, 160(27), 53-56.

10. Ripley, A. (2003). The night detective. Time, 160(27), 45-50.

11. Stewart, J. B. (1991). Scenes from a scandal: The secret world of Michael Milken and Ivan Boesky. The Wall Street Journal, B8.

12. The wall street journal workplace-ethics quiz. The Wall Street Journal, October 21, 1999, B1. Retrieved June 3, 2005, from http://www.cnn.com/2004LAW/03/05/stewart.main/.

13. Verkuyten, M. \& Slooter, L. (2007). Tolerance of Muslim beliefs and practices: Age related differences and context effect. International Journal of Behavioral Development, 31(5), 467-477.

\section{NOTES}


NOTES 